\title{
Correction of Depressed Scars with PRP Enriched Fat Graft
}

\author{
HELMY H. SHALABY, M.D. and SAMEH E. EL-SHAWADFY, M.D. \\ The Department of Plastic and Reconstructive Surgery, Faculty of Medicine, Tanta University
}

\begin{abstract}
Background: Many options for the improvement of depressed scars include scar revision with an elliptical excision, z-plasty, w-plasty, and geometric broken-line closure were found. Dermabrasion and laser treatment has been used to obtain a uniform skin surface. Hypertrophic scars can be treated with intralesional steroids and silicone pressure. Occasionally, scars may be adherent to the underlying structure. This depression along the length of the scar worsens the aesthetic deformity. Fat injection is an established method for treating depressions and contour deformities. Addition of PRP to fat grafts offers a better fat grafting survival.
\end{abstract}

Material and Methods: We report encouraging results with the injection of the PRP enriched fat into a pocket made with a sharp cannula in treating 20 patients with depressed and adherent scars.

Conclusion: This technique is a useful addition to the surgeon's resources when treating scars.

\section{INTRODUCTION}

Scars are areas of fibrous tissue that replace normal skin after injury. They results from the biological process of wound repair in the skin and other tissues of the body and constitutes a natural part of the healing process. Scarring is considered abnormal when the amount of fibrosis is excessive or suboptimal, as in hypertrophic, atrophic, or keloidal scars; when it affects normal function; and when they are disfiguring [1].

Scars on different parts of the body may cause functional disability and cosmetic disfigurements. But when the location is on obvious areas as face or arms the scars need special attention [2].

The selection of autologous graft materials is accepted as one of the most fundamental media for use in most soft-tissue augmentation and reconstruction purposes. Fat grafting affords a medium that is soft, pliable, and readily available in abundant stores; can be harvested with minimal morbidity; has low antigenicity; and lacks risk of disease transmission [3].

Studies were focused on the effects of enhancing fat-graft survival by augmenting the biochemical healing potential of the graft material with the addition of platelet-rich plasma (PRP) [4].
Addition of PRP to fat grafts offers a better graft survival, a less bruising and inflammation reaction, and easier application due to liquefaction effect of PRP [5].

Fat grafts collected by liposuction can be reinjected subcutaneously for correction of depressed or irregular areas [6] which is revascularized within $48 \mathrm{~h}$. During this time, it is fed by diffused materials from plasma [7].

PRP maintains a high concentration of bioactive proteins and growth factors that are shown to augment tissue repair and regeneration. Results of researches have suggested that growth factors not only influence the viability of transferred cells but also may play a bioactive role in influencing the differentiation of precursor adipocytes within the graft into their mature form [8].

In addition to a volumizing effect, the injected fat has a neoangiogenic effect improving the cutaneous elasticity. This technique is thus also recommended for wound healing, scar reduction, radiodermatitis treatment $\&$ correction of acne scars [9].

\section{MATERIAL AND METHODS}

The study was performed on 20 patients with depressed scars of various etiologies in the period between March 2015 and May 2017 at The Plastic and Reconstructive Surgery Department, Tanta University Hospitals.

Patients were treated by autologous fat grafting mixed with Platelet rich plasma (PRP) and 2 sessions of PRP prior to fat grafting with 2 weeks apart.

The procedure was done with local or general anesthesia, according to patient/physician preference. The abdomen or flanks were chosen as donor areas depending on patient/physician preference.

Infiltration was performed in the donor site according to the tumescent technique with a solution containing normal sterile saline containing $0.05 \%$ xylocaine with 1:1,000,000 of epinephrine, at a ratio of $1 \mathrm{ml}$ of solution per milliliter of aspi- 
rated tissue. Manual harvesting using low pressure vacuum, created by slowly withdrawing the plunger of a $10 \mathrm{ml}$ Luer-lock syringe in a gradual manner. The fat harvesting was performed with a $3-\mathrm{mm}$ diameter blunt tip cannula attached to a $10 \mathrm{ml}$ Luerlock syringe. The aspirate was collected in sterile tubes to be centrifuged before injection.

The Harvested fat was centrifuged 3 minutes at $3000 \mathrm{rpm}$. This method separates fat from substances that increase degradation, and concentrates adipocytes and stem cells per milliliter of transplanted fat.

During the procedure blood was withdrawn from the patient with citrate phosphate dextrose (CPD) at a volume ratio of 9 to 1 for anticoagulation. PRP was produced through centrifugal separation of whole blood.

After the first centrifugation $(2500 \mathrm{rpm}, 5$ minutes), the blood was separated into plasma and red blood cells. The red blood cells were removed, and after a further centrifugation (3500 rpm, 5min) of the remaining plasma, the bottom layer, which is rich in platelets and constituted approximately $10 \%$ of the total withdrawn blood volume, was collected for use as PRP. At the time of grafting, the solution was mixed with $2 \%$ calcium chloride at a volume ratio of 7 to 1 to promote the release of growth factors from the platelets.

The purified fat by centrifugation was mixed through a 3-ways connector with PRP.

The fat/PRP mixture was transferred from $10 \mathrm{ml}$ Luer-Lock syringes to $1 \mathrm{ml}$ or $3 \mathrm{ml}$ Luer-Lock syringes via a 3 -ways connector. It is important to use smaller syringe, because the fat placement is more precise. For fat placement, special blunt cannula $(2 \mathrm{~mm})$ was connected to the 1 or $3 \mathrm{ml}$ syringes. Fat was injected in small parcels and thin strips in several layers. Before injection, we created some tunnels in scars, to release fibrotic tissues. The fat graft is then placed by a withdrawing way.

Patients were dressed in compression garments that cover the areas that have been suctioned. Compression garments are generally encouraged 24 hours per day for 4 weeks. Patients were followed up for scar evaluation concerning texture, clinical improvement and complications.

\section{RESULTS}

Twenty patients with depressed scars were included. The epidemiological and clinical features are listed in Table (1). Patients consisted of 9 women $(45 \%)$ and 11 men (55\%). The average age was 24.25 (range 6-41). The most common recipient site was the cheek (40\%). Other treatment areas were the forehead, chin, neck, leg and back area (in 3, 2, 2, 4 and 1 patients respectively). Fat tissue donor sites were the flanks and lower abdomen. The most common etiology was trauma (60\%) while burn was is 6 patients and steroid injection in 2 patients. The scar was linear in 11 patients and wide in 9 patients. Patients received an average of 1.75 fat injections (range 1-3 sessions). Patients were evaluated clinically with serial photographs. Two blinded doctors performed clinical assessments using the following grading scale: $0=$ (poor), $1=$ (fair), $2=$ (good), $3=($ excellent $)$, and $4=($ complete). Clinical results are shown in Table (1). Three patients showed fair results (scale 1), 3 patients showed good results (scale 2), 12 patients showed excellent results (scale 3 ) and 2 patients showed complete resolution (scale 4). There were no poor results. Postoperative complications of minimal bruising, pain, edema, and erythema occurred but rarely persisted more than 72 hours.

\begin{tabular}{|c|c|c|c|c|c|c|}
\hline No. & Sex/Age & Scar site & Etiology & Scar shape & Number of injections & Result \\
\hline 1 & $\mathrm{M} / 10$ & Cheek & Traumatic & Linear & 1 & 3 \\
\hline 2 & $\mathrm{~F} / 25$ & Forehead & Traumatic & Wide & 1 & 3 \\
\hline 3 & $\mathrm{~F} / 31$ & Cheek & Burn & Wide & 3 & 2 \\
\hline 4 & M/17 & Chin & Traumatic & Linear & 1 & 3 \\
\hline 5 & $\mathrm{M} / 41$ & Forehead & Traumatic & Linear & 2 & 3 \\
\hline 6 & $\mathrm{~F} / 6$ & Cheek & Steroid injection & Wide & 2 & 4 \\
\hline 7 & $\mathrm{M} / 22$ & Cheek & Traumatic & Linear & 1 & 2 \\
\hline 8 & $\mathrm{~F} / 23$ & Chin & Traumatic & Linear & 1 & 3 \\
\hline 9 & $\mathrm{~F} / 36$ & Neck & Burn & Wide & 2 & 1 \\
\hline 10 & $\mathrm{M} / 33$ & Forehead & Traumatic & Linear & 1 & 3 \\
\hline 11 & $\mathrm{~F} / 19$ & Cheek & Traumatic & Linear & 1 & 4 \\
\hline 12 & $\mathrm{M} / 22$ & Leg & Burn & Wide & 3 & 2 \\
\hline 13 & $\mathrm{~F} / 27$ & Neck & Burn & Wide & 2 & 3 \\
\hline 14 & $\mathrm{M} / 33$ & Cheek & Traumatic & Linear & 2 & 3 \\
\hline 15 & $\mathrm{~F} / 34$ & Leg & Burn & Wide & 3 & 1 \\
\hline 16 & $\mathrm{M} / 27$ & Back & Steroid injection & Wide & 2 & 3 \\
\hline 17 & $\mathrm{~F} / 20$ & Leg & Burn & Wide & 3 & 3 \\
\hline 18 & $\mathrm{M} / 15$ & Cheek & Traumatic & Linear & 1 & 3 \\
\hline 19 & $\mathrm{M} / 14$ & Cheek & Traumatic & Linear & 1 & 1 \\
\hline 20 & $\mathrm{M} / 30$ & Leg & Traumatic & Linear & 2 & 3 \\
\hline
\end{tabular}

Grading scale for improvement $0=$ (Poor). $\quad 1=$ (Fair). $\quad 2=($ Good $) . \quad 3=($ Excellent $) . \quad 4=($ Complete $)$. 

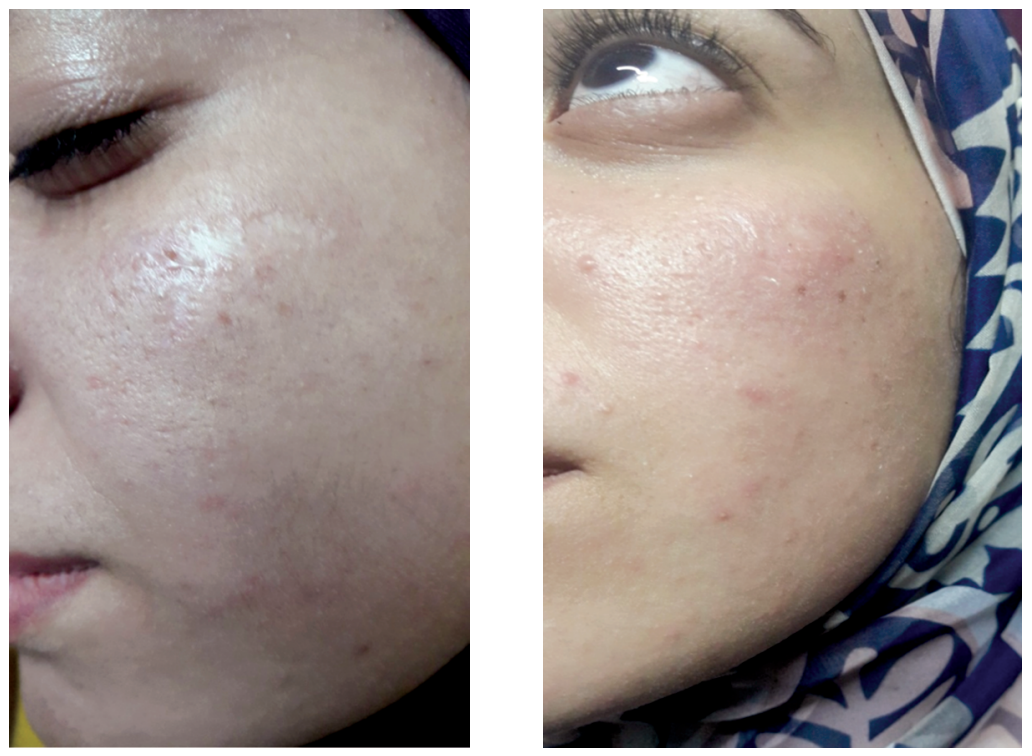

Fig. (1): (A) Pre and (B) Post operative views of a post surgical cheek scar.
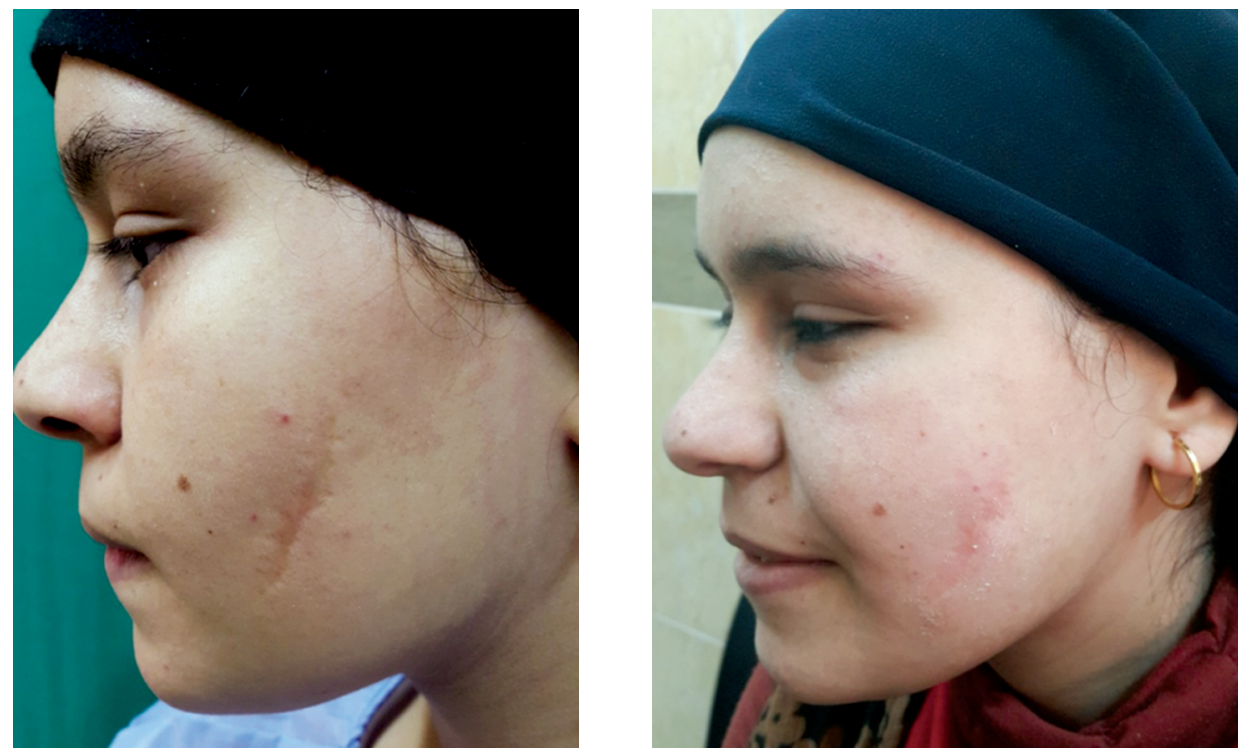

Fig. (2): (A) Pre and (B) Post operative views of a post traumatic cheek scar.
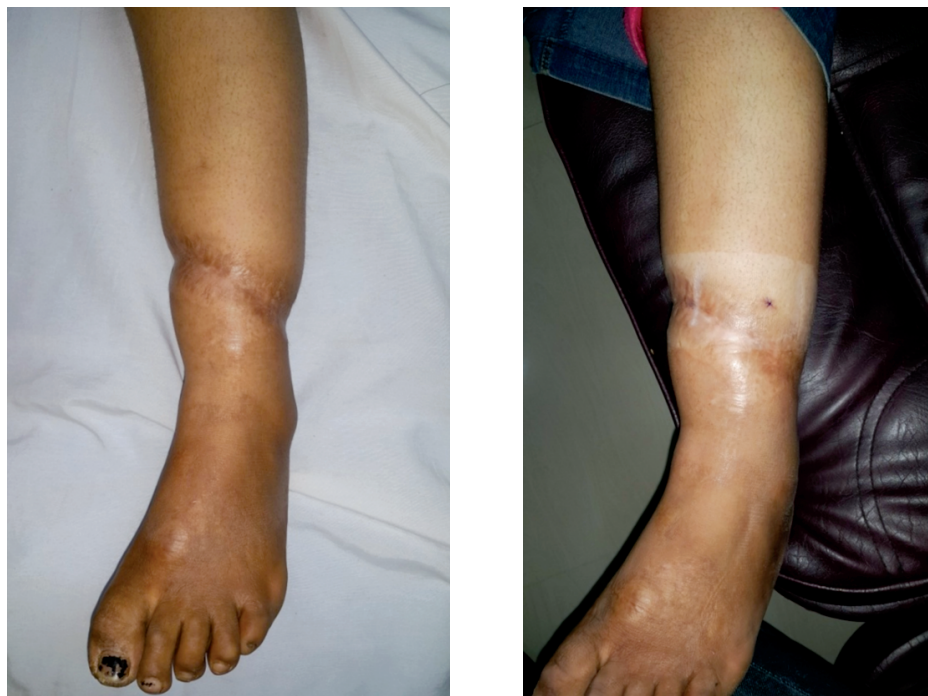

Fig. (3): (A) Pre and (B) Post operative views of a traumatic scar of the leg. 

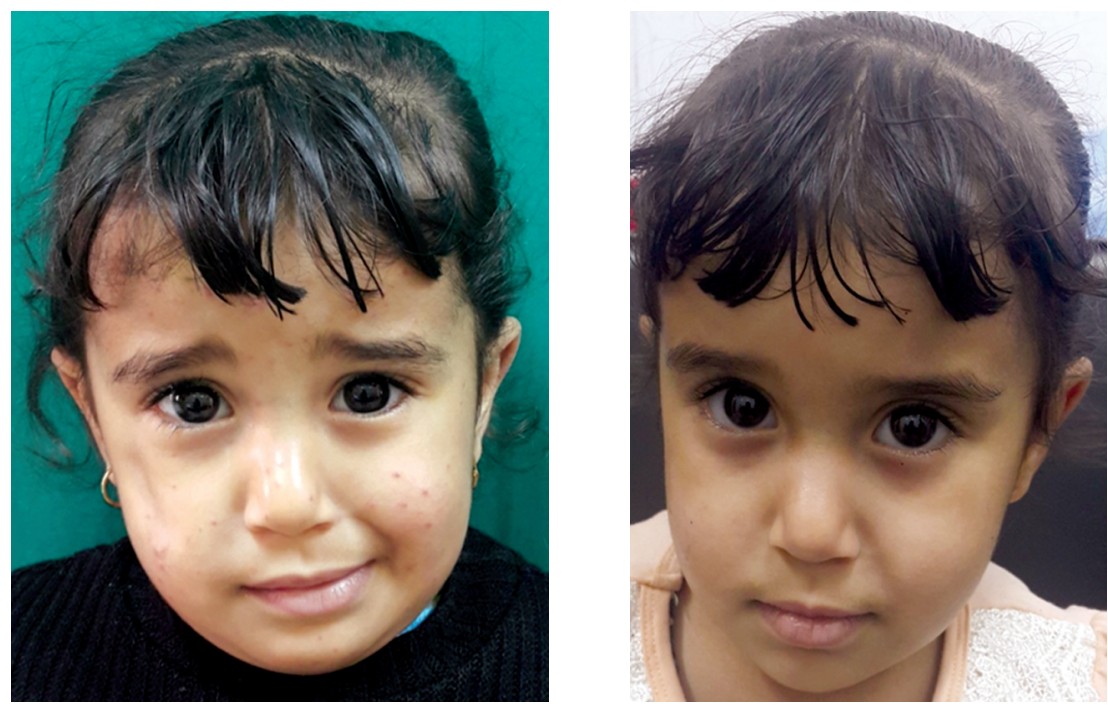

Fig. (4): (A) Pre and (B) Post operative frontal views of a post steroid injection cheek scar.
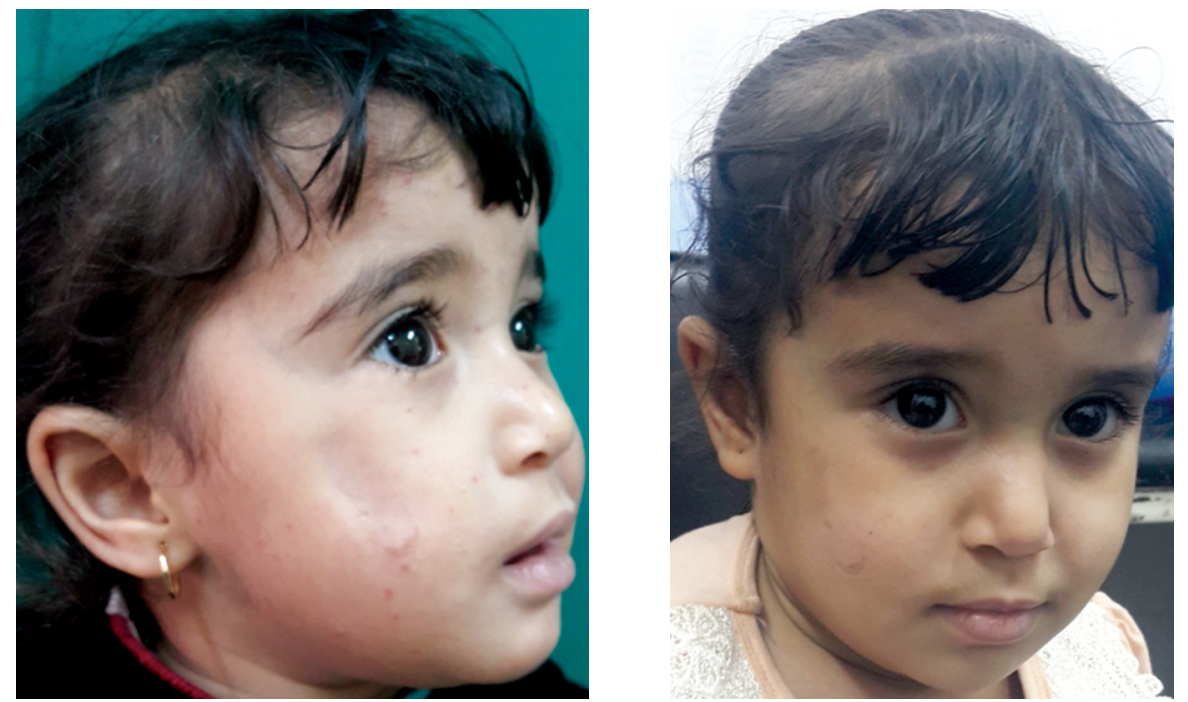

Fig. (5): (A) Pre and (B) Post operative frontal views of a post steroid injection cheek scar.

\section{DISCUSSION}

The advent of fat grafting or lipofilling, first introduced by Neuer in 1893 [10] and popularized by Coleman [6], has changed the surgical strategy for soft tissue augmentation. The application of this technology in patients with scars is a novel surgical alternative and promises long-term effects [12]. They are usually implanted into the superficial layer just beneath the dermis to replace lost tissue volume and induce collagen production via stretching of dermal fibroblasts, thus improving skin texture and thickness [13]. However, the reported rates of fat cell survival are very variable, may be due to different techniques of harvesting, processing and reinjection of fat cells. Recently, the addition of PRP has been considered very effective to improve fat intake and survival [14], and several studies have already demonstrated improvement of wound healing and fat grafting survival in both reconstructive and aesthetic cases by using fat grafting with PRP [15]. Platelet-rich plasma is used as an additive in various clinical indications [1527] including fat grafting. The growth factors present in platelet-rich plasma stimulate wound healing $[\mathbf{2 8 , 2 9}$ ] tissue remodeling, and revascularization [15] and improve fat graft take [30-32]. Clinical studies, however, report a large variation of results [33-35]. Our results confirmed that a combined approach should be the gold standard to maximize the outcome in the treatment of atrophic scars. Fat plus PRP subcutaneous injection can fill the scars and stimulate self-regeneration, as shown in all our patients. 


\section{Conclusion:}

Scars that involve the cutaneous and subcutaneous tissues benefit from a combined approach of fat enriched with PRP that proved to significantly increase skin and subcutaneous tissue thickness. All patients, regardless of age, social class or educational level, are highly motivated to undergo the procedure because they have not yet found effective therapy or have not yet undergone treatment.

\section{REFERENCES}

1- Trivedi N. and Vhankade R.: Minimizing Facial and Periocular Scars. Gujarat Medical Journal, 67: 104-109, 2012.

2- Young I.O., Joon B.K. and Nam M.K.: Depressed Facial Scars Successfully Treated with Autologous Platelet-Rich Plasma and Light-Emitting Diode Phototherapy at 830 nm. Ann. Dermatol., 26: 417-418, 2014.

3- Sadati K., Alexander R. and Corrado A.: Platelet-Rich Plasma (PRP) Utilized To Promote Greater Graft Volume Retention in Autologous Fat Grafting. The American Journal of Cosmetic Surgery, 23: 203-211, 2006.

4- Jin R., Zhang L. and Zhang Y.G.: Does platelet-rich plasma enhance the survival of grafted fat? An update review. Int. J. Clin. Exp. Med., 6: 252-258, 2013.

5- Modarressi A.: Platlet Rich Plasma (PRP) Improves Fat Grafting Outcomes. World J. Plast. Surg., 2: 6-13, 2013.

6- Coleman S.R.: Structural fat grafting: More than a permanent filler. Plast. Reconstr. Surg., 118 (3 Suppl): 108S120S, 2006.

7- Toledo L.S. and Mauad R.: Fat injection: A 20-year revision. Clin. Plast. Surg., 33: 47-53, 2006.

8- Santrach P.J., et al.: Laboratory Validation of autologous platelet gel. Transfusion, 44 (Supp1): 68A-69A, 2004.

9- Marco K., Marazzi M., Luisa Torre M.L. and Vigo D.: Fat injection for cases of severe burn outcomes: A new perspective of scar remodeling and reduction. Aesthetic Plast. Surg., 32: 465-9, 2008.

10- Tenna A., Cogliandro M., Barone Vincenzo, Panasiti M., Tirindelli Carolina Nobile and Paolo Persichett: Comparative Study Using Autologous Fat Grafts Plus PlateletRich Plasma With or Without Fractional CO2 Laser Resurfacing in Treatment of Acne Scars: Analysis of Outcomes and Satisfaction With FACE-Q S. Aesth. Plast. Surg., 41: 661-666, 2017.

11- Barret J.P., Sarobe N., Grande N., Vila D. and Palacin J.M.: Maximizing results for lipofilling in facial reconstruction. Clin. Plast. Surg., 36: 487-492, 2009.

12- Wang F., Garza L.A., Kang S., Varani J., Orringer J.S., Fisher G.J. and Voorhees J.J.: In vivo stimulation of de novo collagen production caused by cross-linked hyaluronic acid dermal filler injections in photodamaged human skin. Arch. Dermatol., 143: 155-163, 2007.

13- Cervelli V., Palla L., Pascali M., De Angelis B., Curcio B.C. and Gentile P.: Autologous platelet-rich plasma mixed with purified fat graft in aesthetic plastic surgery. Aesthetic Plast. Surg., 33: 716-721, 2009.
14- Modarressi A.: Platlet rich plasma (PRP) improves fat grafting outcomes. World J. Plast. Surg., 2: 6-13, 2013.

15- Liao H.T., Marra K.G. and Rubin J.P.: Application of platelet-rich plasma and platelet-rich fibrin in fat grafting: Basic science and literature review. Tissue Eng. Part B Rev., 20: 267-276, 2014.

16- Ramos-Torrecillas J., Luna-Bertos E.D., Manzano-Moreno F.J., Garcia-Martinez O. and Ruiz C.: Human fibroblastlike cultures in the presence of platelet-rich plasma as a single growth factor source: Clinical implications. Adv. Skin Wound Care, 27: 114-120, 2014.

17- Shin M.K., Lee J.W., Kim Y.I., Kim Y.O., Seok H. and Kim N.I.: The effects of platelet-rich clot releasate on the expression of MMP-1 and type I collagen in human adult dermal fibroblasts: PRP is a stronger MMP-1 stimulator. Mol. Biol. Rep., 41: 3-8, 2014.

18- Kushida S., Kakudo N., Suzuki K. and Kusumoto K.: Effects of platelet-rich plasma on proliferation and myofibroblastic differentiation in human dermal fibroblasts. Ann. Plast. Surg., 71: 219-224, 2013.

19- Graziani F., Ivanovski S., Cei S., Ducci F., Tonetti M. and Gabriele M.: The in vitro effect of different PRP concentrations on osteoblasts and fibroblasts. Clin. Oral Implants Res., 17: 212-219, 2006.

20- Yamaguchi R., Terashima H., Yoneyama S., Tadano S. and Ohkohchi N.: Effects of platelet-rich plasma on intestinal anastomotic healing in rats: PRP concentration is a key factor. J. Surg. Res., 173: 258-266, 2012.

21- Kim J.H., Jung M., Kim H.S., Kim Y.M. and Choi E.H.: Adipose-derived stem cells as a new therapeutic modality for ageing skin. Exp. Dermatol., 20: 383-387, 2011.

22- Trojahn Kolle S.F., Oliveri R.S., Glovinski P.V., Elberg J.J., Fischer- Nielsen A. and Drzewiecki K.T.: Importance of mesenchymal stem cells in autologous fat grafting: A systematic review of existing studies. J. Plast. Surg. Hand Surg., 46: 59-68, 2012.

23- Przybyt E., Krenning G., Brinker M.G. and Harmsen M.C.: Adipose stromal cells primed with hypoxia and inflammation enhance cardiomyocyte proliferation rate in vitro through STAT3 and Erk1/2. J. Transl. Med., 13: 11-39, 2013.

24- De Mos M., Van Der Windt A.E., Jahr H., et al.: Can platelet-rich plasma enhance tendon repair? A cell culture study. Am. J. Sports Med., 36: 1171-1178, 2008.

25- Burgess W.H., Mehlman T., Friesel R., Johnson W.V. and Maciag T.: Multiple forms of endothelial cell growth factor: Rapid isolation and biological and chemical characterization. J. Biol. Chem., 260: 11389-11392, 1985.

26- Carpentier G., Martinelli M., Courty J. and Cascone I.: Angiogenesis analyzer for Image J. In: $4^{\text {th }}$ Image J. User and Developer Conference Proceedings. MondorflesBains, Luxembourg; October 24-26, 2012 (ISBN 2919941-18-6), 198-201, 2012.

27- Eppley B.L., Pietrzak W.S. and Blanton M.: Platelet-rich plasma: A review of biology and applications in plastic surgery. Plast. Reconstr. Surg., 118: 147e-159e, 2006.

28- Cervelli V., Gentile P., Scioli M.G., et al.: Application of plateletrich plasma in plastic surgery: Clinical and in vitro evaluation. Tissue Eng. Part C Methods, 15: 625-634, 2009. 
29- Engebretsen L., Steffen K., Alsousou J., et al.: IOC consensus paper on the use of platelet-rich plasma in sports medicine. Br. J. Sports Med., 44: 1072-1081, 2010.

30- Oh D.S., Cheon Y.W., Jeon Y.R. and Lew D.H.: Activated platelet-rich plasma improves fat graft survival in nude mice: A pilot study. Dermatol. Surg., 37: 619-625, 2011.

31- Rodriguez-Flores J., Palomar-Gallego M.A., EnguitaValls A.B., Rodriguez-Peralto J.L. and Torres J.: Influence of plateletrich plasma on the histologic characteristics of the autologous fat graft to the upper lip of rabbits. Aesthet. Plast. Surg., 35: 480-486, 2010.

32- Gentile P., Orlandi A., Scioli M.G., et al.: A comparative translational study: The combined use of enhanced stromal vascular fraction and platelet-rich plasma improves fat grafting maintenance in breast reconstruction. Stem Cells Transl. Med., 1: 341-351, 2012.

33- Salgarello M., Visconti G. and Rusciani A.: Breast fat grafting with platelet-rich plasma: A comparative clinical study and current state of the art. Plast. Reconstr. Surg., 127: 2176-2185, 2011

34- Fontdevila J., Guisantes E., Martnez E., Prades E. and Berenguer J.: Double-blind clinical trial to compare autologous fat grafts versus autologous fat grafts with PDGF: No effect of PDGF. Plast. Reconstr. Surg., 134: 219e-230e, 2014. 